\title{
Aulas Dinâmicas e Interativas \\ Uma Leitura Freiriana da Compreensão \\ de Estudantes de Pedagogia \\ a Respeito da Docência
}

\author{
Márden de Pádua Ribeiro ${ }^{1}$ \\ Nayara Alves Teixeira ${ }^{2}$ \\ Flávia Raiane de Jesus Ramos ${ }^{3}$
}

\begin{abstract}
$\underline{\text { Resumo }}$
0 presente artigo trata-se de uma pesquisa quantitativa realizada em um curso de Pedagogia privado de Belo Horizonte. Tal pesquisa teve por objetivo levantar o perfil dos discentes do referido curso. Por meio de questionário estruturado contendo questões fechadas e abertas, a pesquisa pôde estabelecer esse levantamento a partir de três eixos estruturantes: pessoal, cultural e pedagógico. 0 foco deste artigo diz respeito às análises provenientes das respostas contidas no eixo pedagógico do questionário. Neste eixo foi perguntado aos discentes o que compreendiam como uma aula "boa" e uma aula "ruim". A questão foi aberta e o tratamento específico desse dado foi qualitativo, a partir de análise esmiuçada das respostas sob auxílio metodológico da análise de conteúdo. Foi possível perceber nas respostas dos discentes um determinado perfil de docência que compreendem. As análises das respostas tiveram como base a teoria de Paulo Freire.
\end{abstract}

Palavras-chave: Pedagogia. Aula. Análise de conteúdo.

1 Doutorando em Educação - PUCMG. Professor do curso de Pedagogia - FACISABH. Coordenador do Grupo de Estudo e Pesquisa de Formação Docente (Gepfor - FACISABH). Integrante da Rede Freireana de Pesquisadores. mardendepadua@yahoo.com.br

2 Graduada em Pedagogia - FACISABH. Integrante do Grupo de Estudo e Pesquisa de Formação Docente (Gepfor - FACISABH). alvesnayara94@gmail.com

3 Graduada em Pedagogia - FACISABH. Integrante do Grupo de Estudo e Pesquisa de Formação Docente (Gepfor - FACISABH). flaviaraianeramos@outlook.com 


\title{
DYNAMIC AND INTERACTIVE CLASSES: A FREIRIANA READING OF THE UNDERSTANDING OF PEDAGOGY STUDENTS WITH RESPECT TO TEACHING
}

\begin{abstract}
This article is about a quantitative research carried out in the course of Private Pedagogy of Belo Horizonte. This research aimed to raise the profile of the students of said course. Through a structured questionnaire containing closed and open questions, the research was able to establish this survey from three structuring axes: personal, cultural and pedagogical. The focus of the present article concerns the analysis of the responses contained in the pedagogical axis of the questionnaire. On this axis, students were asked what they understood as a "good" class and a "bad" one. The question was opened and the specific treatment of this data was qualitative, through the analysis scrutinized of the answers under methodological aid of the content analysis. It was possible to perceive in the answers of the students a certain profile of teaching that they understand. The analyzes of the answers were based on the theory of Paulo Freire.
\end{abstract}

Keywords: Pedagogy. Class. Content analysis.

Recebido em: 12/4/2017

Aceito em: 14/12/2017 
Levantar o perfil de estudantes de Pedagogia, futuros profissionais da educação, é fundamental se quisermos compreender com mais profundidade quem são estes sujeitos que irão atuar, em futuro próximo, na formação de crianças e jovens. É desnecessário discorrer sobre a importância da Pedagogia para a sociedade, mas é importante ressaltar que a Pedagogia não se limita apenas à Educação Infantil e aos anos iniciais do Ensino Fundamental, ao contrário, a atuação do pedagogo é mais ampla e abarca também outros espaços educativos, escolares ou não (BRASIL, 2006).

É nesse contexto que se iniciou uma pesquisa realizada em um curso de Pedagogia de instituição privada de Belo Horizonte. Tal pesquisa teve por objetivo realizar um levantamento do perfil destes discentes, a partir de um questionário estruturado que contemplou todos os períodos do curso em questão. Tal levantamento ficou a cargo do grupo de pesquisa oriundo do curso e durante o ano de 2015 foram coletados os dados referentes aos questionários. Após a coleta o grupo iniciou o processo de análise dos dados, no intuito não só de problematizar os desafios referentes ao curso em si, como também de socializar as conclusões com a comunidade científica, de modo a permitir o diálogo e a interação com outras pesquisas de temática semelhante.

O questionário foi dividido em três grandes eixos: pessoal, cultural e pedagógico. Tais eixos foram separados apenas para fins didáticos, tendo em vista que tais dimensões se interpenetram na subjetividade de cada um e não podem ser compreendidas de modo isolado. No eixo pessoal, foram levantadas questões como: idade, religião, moradia, profissão, gênero, etc. No eixo cultural investigou-se a frequência (frequentemente, raramente, nunca) com que participavam de eventos culturais (teatro, shows, cinemas, palestras, feiras, etc.). No último eixo do questionário, foco do presente artigo, denominado "pedagógico", foram selecionadas perguntas objetivas (abertas), entre as quais se destacam aqui: “O que é uma boa aula para você?"; "O que é uma aula ruim para você?". O recorte do presente artigo, portanto, trata-se justamente da análise dos dados provenientes destas questões de caráter mais pedagógico voltadas especialmente para a investigação da compreensão dos estudantes a respeito da docência. 
O grupo de pesquisa, após analisar os dados a partir de referenciais teórico-metodológicos específicos, problematizou as respostas obtidas nos questionários e chegou à conclusão de que os dados contidos ali poderiam ser lidos e interpretados a partir da obra de Paulo Freire. Assim, à luz do referencial freiriano, o presente artigo pretende analisar e problematizar as compreensões de estudantes de Pedagogia a respeito do que entendem por uma aula boa e ruim. A obra freiriana fornece um arcabouço teórico potente a respeito da docência e como afirma Saul (2016), um dos desafios atuais no campo educacional, em especial dos interessados na obra freiriana, é justamente a necessidade de ressignificar sua teoria por meio de pesquisas atuais. Em outras palavras, muito mais do que elaborar textos que se limitem a reproduzir incansavelmente as clássicas concepções de Paulo Freire, é tarefa dos pesquisadores se apossar dos referenciais freirianos a partir de problemáticas concretas da atualidade.

Abordar a temática da aula para discentes do curso de Pedagogia é para nós uma questão crucial. Não queremos defender aqui que a Pedagogia se limita à docência, pois concordando com Libâneo (2006) a base de um curso de Pedagogia não pode se reduzir à docência. A Pedagogia é o estudo amplo e complexo do fenômeno educativo. É desse modo que o autor compreende que todo trabalho docente é um trabalho pedagógico, mas nem todo trabalho pedagógico é trabalho docente. A docência, no entanto, é componente central nos cursos de Pedagogia, como pode ser observado nas Diretrizes Curriculares da Pedagogia:

Art. $2^{\circ}$ As Diretrizes Curriculares para o curso de Pedagogia aplicam-se à formação inicial para o exercício da docência na Educação Infantil e nos anos iniciais do Ensino Fundamental, nos cursos de Ensino Médio, na modalidade Normal, e em cursos de Educação Profissional na área de serviços e apoio escolar, bem como em outras áreas nas quais sejam previstos conhecimentos pedagógicos.

$\S 1^{\circ}$ Compreende-se a docência como ação educativa e processo pedagógico metódico e intencional, construído em relações sociais, étnico-raciais e produtivas, as quais influenciam conceitos, princípios e objetivos da Pedagogia, desenvolvendo-se na articulação entre conhecimentos científicos e culturais, 
valores éticos e estéticos inerentes a processos de aprendizagem, de socialização e de construção do conhecimento, no âmbito do diálogo entre diferentes visões de mundo (BRASIL, 2006, p. 11).

É conhecida a crítica que Franco, Libâneo e Pimenta (2007) fazem às Diretrizes, pois entendem que esta legislação resume a Pedagogia à docência e infelizmente não considera o estudo do fenômeno educativo em todas as suas dimensões, compreendendo os elementos da ação educativa e sua contextualização. Reitera-se aqui, portanto, que apesar de enfatizar essas duas questões referentes à docência, não defendemos a Pedagogia como uma ciência limitada a essa questão. No caso da referida pesquisa, foi objetivo compreender como discentes do curso de Pedagogia compreendiam a docência, nomeadamente "aula", e como adjetivariam esta docência. Masetto (2003) define aula como um grupo (coletivo) de pessoas que busca um objetivo comum: a aprendizagem mediante a análise de problemas, pesquisas, experiências, vivências, leituras, etc.

Por essa razão, os adjetivos "boa" e "ruim", foram propositalmente colocados nas perguntas. Não foi nosso interesse perguntar "O que é uma aula para você?" Não queríamos compreender o conceito dos discentes a respeito da aula, e sim, captar suas compreensões em meio aos juízos de valor, contidos no que seria uma aula boa e ruim, a partir de suas construções teóricas, ideológicas e subjetivas adquiridas durante o curso e evidentemente fora dele, por meio de suas práticas profissionais. Assim, compreendemos que ao adjetivar a aula, os discentes acabam por fornecer sinais importantes a respeito de suas próprias concepções acerca da educação. É também por essa razão que essas perguntas foram abertas, ainda que tal opção metodológica envolvesse imenso trabalho para produzir e categorizar os dados provenientes de múltiplas e extensas respostas.

É importante relatar sucintamente, mesmo não sendo o foco do presente artigo, as conclusões gerais dos outros eixos (pessoal, cultural) do questionário, de modo que ofereça ao leitor um panorama geral do perfil dos estudantes de Pedagogia da instituição.

De um modo geral, foi possível constatar que se trata de um curso predominantemente associado ao gênero feminino (98\%), indo ao encontro de todo o processo histórico de "feminização" do magistério, sobretudo a partir do 
período imperial brasileiro, no século 19, acentuando-se com a industrialização acelerada e precária no período da Primeira República, do início do século 20, até se consolidar nos dias atuais, como bem explica Tanuri (2000).

No item destinado à moradia foi possível constatar que a maioria dos discentes reside em regiões periféricas de Belo Horizonte, o que implica longos trajetos da faculdade até a residência, seja na volta para a casa, seja na ida para a faculdade, ou, até mesmo, do trabalho para a faculdade e desta para a residência. Os discentes que moram na própria Belo Horizonte concentram-se em bairros considerados distantes da instituição. O perfil socioeconômico dos alunos, em sua esmagadora maioria, revela que são oriundos de camadas populares, majoritariamente dependentes de programas do governo federal, tais como o Fundo de Financiamento Estudantil (Fies) e o Programa Universidade para Todos (Prouni).

Um dado relevante diz respeito à questão religiosa. Somadas, as religiões católica e protestante correspondem a $96 \%$ do corpo discente. O número de estudantes que se declararam católicos é $33 \%$ superior ao percentual daqueles que se declararam protestantes. Um alto número de estudantes que se declaram cristãos é sempre relevante na formação de professores, tendo em vista a emergência de assuntos centrais e polêmicos que permeiam o atual campo da educação. Temáticas como o gênero e a sexualidade, bem como os desafios da tolerância religiosa, especialmente aquelas de origem africana, são hoje questões fundamentais para qualquer estudante que almeja, efetivamente, trabalhar no campo educacional.

No que respeita à faixa etária, o curso se mostrou majoritariamente jovem. A faixa preponderante concentrou-se entre 18-25 anos, seguido do recorte de 26-30 anos. Juntos, se estendermos a faixa dos 18 aos 30, mais da metade dos estudantes são contemplados. O número de discentes com mais de 50 anos chega a $20 \%$ e também não pode ser considerado desprezível. Tal diversidade geracional certamente é enriquecedora ao curso e compete aos docentes lidar com este desafio. Vale ressaltar ainda que $75 \%$ dos discentes conciliam o curso com algum tipo de trabalho. Destes, $26 \%$ já atuam na área educacional.

Existem diversos trabalhos que realizaram um levantamento do perfil de estudantes do curso de Pedagogia. Procurando na base de dados do Scielo, no Google Acadêmico e no Portal de Teses da Capes encontramos, entre 2005 
e 2015, 19 pesquisas destinadas especificamente a este levantamento de perfil, no entanto em nenhuma delas foi possível identificar o interesse em investigar e sondar a compreensão que estudantes de Pedagogia possuem em relação às aulas/docência. Desse modo, defendemos aqui que tal questão problematizada em nosso questionário representa uma relativa originalidade em relação a essas pesquisas coletadas. Por essa razão é que decidimos no presente trabalho enfatizar a análise dos dados referentes a essas duas complexas perguntas: "O que é uma boa aula para você?"; "O que é uma aula ruim para você?"

Das pesquisas levantadas, é interessante mencionar alguns dados convergentes com o panorama geral do perfil encontrado em nossa pesquisa. Gutierres et al. (2012) ao pesquisarem em instituição privada do Rio Grande do Sul, também perceberam um alunado de Pedagogia majoritariamente jovem, feminino e oriundo de camadas populares. Reis e Medeiros (2011, p. 1) pesquisando alunos de Pedagogia da Universidade Federal de Goiás, também concluíram a respeito de um perfil majoritariamente feminino, jovem, "de classe média baixa, solteira, e que optou pelo curso pela perspectiva no mercado de trabalho". A mesma conclusão é percebida na pesquisa de Santos e Velanga (2010) com discentes da Universidade Federal de Rondônia e no estudo de Flores (2015) no Mato Grosso. Pode-se inferir, então, que há uma certa convergência no perfil atual dos cursos de Pedagogia no Brasil: estudantes do gênero feminino, perfil etário jovem, oriundos de camadas populares, vinculação religiosa cristã e crença no acesso ao Ensino Superior como mecanismo de ascensão social.

Isso posto, antes de adentrarmos no recorte estabelecido para o presente artigo, é fundamental explicarmos de modo mais aprofundado os aportes metodológicos que nortearam a realização da pesquisa.

\section{Aportes Metodológicos}

De um modo geral, a pesquisa realizada pelo grupo é quantitativa (GIL, 2002) e utilizou como técnica de produção dos dados o questionário estruturado. Ao tratar especificamente dos dados provenientes do eixo pedagógico, no entanto, a análise foi qualitativa. Ao perguntarmos aos estudantes, de modo 
aberto, o que entendem por aula boa e ruim, buscamos analisar uma a uma das respostas, visando a problematizá-las, captar distanciamentos e agrupamentos possíveis, para posteriormente elencarmos categorias de análise com base na avaliação de conteúdo teorizada pioneiramente por Bardin (2011). É por essa razão que defendemos que, ao mesmo tempo que a pesquisa como um todo, de levantamento de perfil dos estudantes, seja quantitativa, a análise dos dados referentes ao eixo pedagógico se deu de modo qualitativo.

Para Lakatos e Marconi (2005) o questionário é constituído por uma série ordenada de perguntas, que devem ser respondidas por escrito pelo pesquisado, de preferência sem a presença do pesquisador. Junto com o questionário deve ser enviada uma carta explicando a pesquisa e garantindo o anonimato do entrevistado. Esse instrumento apresenta como vantagens atingir maior número de pessoas simultaneamente; proporciona maior liberdade nas respostas, em razão do anonimato; oferece menos risco de distorção pela não influência do pesquisador e há mais tempo para responder o questionário e em hora mais favorável.

Como limitações, podem ser apontadas a porcentagem reduzida dos questionários que retornam; a impossibilidade de auxiliar o informante em questões mal compreendidas; o desconhecimento das circunstâncias em que foram preenchidos os questionários torna difícil o controle e a verificação (LAKATOS; MARCONI, 2005). A utilização de um questionário estruturado, no entanto, mostrou-se uma técnica mais eficaz, na medida em que a maioria das questões não apresentava uma complexidade que demandasse dúvidas durante a resolução.

$\mathrm{O}$ uso do questionário permitiu aos pesquisadores maior agilidade na tabulação dos dados, ainda que nem todo ele fosse composto por questões fechadas. Segundo Gil (2002), não é muito comum este recurso (questões abertas) em questionários, pois dificulta para ordenar os dados, contudo ainda assim optamos por este tipo de questão em algumas perguntas, pois dariam uma dimensão mais exata do que se objetivava pesquisar. Os questionários foram aplicados durante o ano de 2015, nos turnos da manhã e da noite do curso de Pedagogia, de forma contínua. 
Eram aplicados durante as aulas, sempre com o consentimento da coordenação do curso e explicação prévia dos objetivos por parte do grupo de pesquisa. A aplicação orientou-se a partir dos seguintes princípios: todos os períodos do curso de Pedagogia seriam contemplados, porém apenas em uma ocasião, de modo que um período não tornará a responder o questionário no semestre seguinte. A participação não foi obrigatória, muito menos estimulada por meio de benefícios avaliativos. Ao todo foram levantados 282 questionários, quase todos respondidos em sua totalidade, de modo que nenhum foi descartado integralmente pelo grupo de pesquisa. Vale destacar que o curso possui um total de sete períodos, totalizando três anos e meio de duração. O sétimo período não participou da pesquisa.

Tabela 1 - Total de questionários

\begin{tabular}{|c|c|}
\hline Período & Questionários respondidos \\
\hline 1 Noite & 27 \\
\hline 2 Noite & 24 \\
\hline 2 Manhã & 32 \\
\hline 3 Noite & 17 \\
\hline 4 Noite & 50 \\
\hline 4 Manhã & 37 \\
\hline 5 Noite & 42 \\
\hline 6 Noite & 27 \\
\hline 6 Manhã & 27 \\
\hline TOTAL & 282 \\
\hline
\end{tabular}

Fonte: Dados da pesquisa, 2017.

Conforme já mencionado, o questionário estruturado pautou-se por três eixos: pessoal, cultural e pedagógico. O foco do eixo pedagógico foi estimular os graduandos a refletirem sobre a docência. Nesse sentido, optamos por adjetivar a noção de aula, dando-lhe características positivas e negativas (aula boa ou ruim). Foi nossa intenção incentivar os alunos, futuros profissionais da educação, a comentar por escrito como definem uma aula como boa e ruim. 
Reitera-se que adjetivar a concepção de aula (boa, ruim) não significa estimular os discentes a estereotipar determinado perfil de docente e sim, refletir didaticamente, à luz de percepções pedagógicas que possuem, como uma aula pode interferir no processo de ensino-aprendizagem e quais conceitos são fundamentais na sua prática.

Questões abertas em questionários oriundos de pesquisa quantitativa resultam em desafio aos pesquisadores. Tabular tais dados, filtrar o que é relevante, não é tarefa fácil. Por essa razão, a pesquisa ancorou-se na investigação de conteúdo de Bardin (2011) para a criação de categorias de análise que pudessem dar uma dimensão mais estruturada para a interpretação e avaliação dos dados.

De acordo com Chizzotti (2008, p. 113), a análise de conteúdo "visa decompor as unidades léxicas ou temáticas de um texto, codificadas sobre algumas categorias, compostas por indicadores que permitam uma enumeração das unidades, e a partir disso, estabelecer inferências generalizadoras". Ainda no que diz respeito à escolha da metodologia de análise de conteúdos para estudo e interpretação dos dados produzidos, Gomes (2000, p. 74) observa que

[...] podemos encontrar respostas para as questões formuladas e também podemos confirmar ou não as afirmações estabelecidas antes do trabalho de investigação (hipóteses). A outra função diz respeito à descoberta do que está por trás dos conteúdos manifestos, indo além das aparências do que está sendo comunicado. As duas funções podem, na prática, se complementar e podem ser aplicadas a partir de princípios da pesquisa quantitativa ou da qualitativa.

Segundo Bardin (2011, p. 128), a análise de conteúdo possui três fases: a primeira seria um estudo prévio, que consiste em escolher os documentos que serão submetidos à análise, no intuito de formular hipóteses e objetivos visando "à elaboração de indicadores que darão sustentação à interpretação final". A segunda fase corresponde à exploração do material coletado, com o intuito de codificar e enumerar os dados recolhidos, categorizando-os. E finalmente, a 
última fase refere-se ao tratamento dos resultados obtidos e sua interpretação, sendo tarefa do pesquisador nesse momento interpretar e apontar as inferências com base nas categorias levantadas na fase anterior. Para Bardin (2011), produzir uma inferência é condição essencial em análises de conteúdo.

Assim, a partir das respostas nos questionários, foi elaborado e sistematizado um conjunto de categorias de análise. Essa atividade "significa agrupar elementos, idéias ou expressões em torno de um conceito capaz de abranger tudo isso" (GOMES, 2000, p. 70). Dessa maneira, as categorias foram estabelecidas em relação direta com os dados coletados, de modo a articular sempre a teoria com as respostas.

[...] Nem sempre a tarefa de formular categorias a partir dos dados coletados é simples. Às vezes, essa tarefa pode se transformar numa ação complexa e isso só pode ser ultrapassado com a fundamentação e a experiência do pesquisador. Por outro lado, a articulação das categorias configuradas a partir dos dados com as categorias gerais também requer sucessivos aprofundamentos sobre as relações entre a base teórica do pesquisador e os resultados por ele investigados (GOMES, 2000, p. 74).

O processo de criação dessas categorias é trabalhoso. Como já mencionado, ao todo foram 282 questionários respondidos, isto é, 282 respostas abertas de estudantes acerca do que é uma aula boa e ruim. A partir desse número volumoso de respostas abertas, começamos então, com base nos procedimentos já explicitados da análise de conteúdo, o processo de interpretação e exame dos dados.

Tal processo ocorreu em etapas: 1) Leitura de todas as 282 respostas pelo grupo de pesquisa, o que para Bardin (2011) é compreendido como uma análise prévia. 2) Formulação de hipóteses e inferências a respeito das primeiras impressões após a leitura. Debate entre o grupo de pesquisa a respeito dessas impressões. 3) Releitura das 282 respostas, buscando identificar termos e expressões que possuíssem semânticas semelhantes. Tal processo foi fundamental para a criação das categorias. A Tabela 2 ilustra como isso se deu: 
Tabela 2 - Criação das categorias de análise

\begin{tabular}{|c|c|}
\hline $\begin{array}{l}\text { Categoria criada pelo } \\
\text { grupo de pesquisa }\end{array}$ & Termos/expressões semanticamente semelhantes \\
\hline Dinamismo/Interação & $\begin{array}{l}\text { "Aula boa é que interage com os alunos" } \\
\text { "Aula dinâmica, interativa" } \\
\text { "Aula participativa, que os alunos interagem" } \\
\text { "Aula dinâmica, que não é cansativa" } \\
\text { "Aula que o professor é dinâmico para passar os conteúdos" }\end{array}$ \\
\hline $\begin{array}{l}\text { Saber transmitir o } \\
\text { conteúdo }\end{array}$ & $\begin{array}{l}\text { "Aula boa é quando o professor sabe passar a matéria" } \\
\text { "É uma aula que o professor consegue transmitir o conteúdo } \\
\text { com clareza" } \\
\text { "É uma aula que todo mundo entende" }\end{array}$ \\
\hline Domínio do conteúdo & $\begin{array}{l}\text { "Aula boa é quando o professor domina o que está falando, } \\
\text { passa segurança" } \\
\text { "Quando a aula demonstra segurança" } \\
\text { "Quando o professor sabe o que está dizendo lá na frente" }\end{array}$ \\
\hline $\begin{array}{l}\text { Articular teoria e } \\
\text { prática }\end{array}$ & $\begin{array}{l}\text { "É quando o professor não fica só na teoria" } \\
\text { "Aula boa é que o professor fornece exemplos concretos e } \\
\text { práticos das teorias" } \\
\text { "É uma aula cheia de exemplos práticos, não fica só na } \\
\text { teoria" }\end{array}$ \\
\hline $\begin{array}{l}\text { Falta de dinamismo/ } \\
\text { aula cansativa }\end{array}$ & $\begin{array}{l}\text { "É uma aula que não é dinâmica" } \\
\text { "Aula cansativa, parada, o professor não interage com os } \\
\text { alunos" }\end{array}$ \\
\hline $\begin{array}{l}\text { Dificuldade na } \\
\text { transmissão }\end{array}$ & $\begin{array}{l}\text { "É uma aula que ninguém entende nada" } \\
\text { "Aula ruim é quando o professor explica, mas não consegue } \\
\text { fazer com que as pessoas aprendam" } \\
\text { "Não consegue passar o conteúdo com clareza" } \\
\text { "Sabe muito, mas não consegue transmitir bem o que sabe" }\end{array}$ \\
\hline Excesso de teorias & $\begin{array}{l}\text { "Aula ruim para mim é quando só tem teoria, não tem nada } \\
\text { de prática" } \\
\text { "Aquela aula que enche o slide de teorias" }\end{array}$ \\
\hline
\end{tabular}

Fonte: Dados da pesquisa, 2017.

Ainda sobre esse processo de criação das categorias, é necessário ressaltar que elas, embora estejam separadas, em muitas respostas se interpenetram. $\mathrm{Ou}$ seja, havia tanto respostas que se limitavam a enfatizar apenas uma abordagem quanto respostas que perpassavam por todas essas dimensões. Após percebermos estas questões chegamos à quarta etapa: 4) Tabulação das respostas em Excel 
para a formulação de gráficos. Após produzirmos as categorias, relemos novamente as respostas articulando-as às categorias criadas, reiterando que às vezes uma mesma resposta era associada a uma ou mais categorias ao mesmo tempo.

É nesse sentido que entendemos que a pesquisa, embora quantitativa em sua essência, tratou especificamente essas respostas de modo qualitativo, pois, mesmo diante de 282 respostas abertas, a pesquisa não se limitou a uma mera descrição desses dados. Pelo contrário, aprofundou as análises, criando categorias, de modo a explorar o máximo possível de interpretação daquelas respostas. Nesse sentido, portanto, entendemos que o tratamento dado à análise específica dessas respostas foi qualitativo, com base em Gil (2002).

Após a produção dos dados e sua devida sistematização com base na análise de conteúdo de Bardin (2011), iniciamos o processo de interpretação e problematização à luz de referenciais teóricos que o grupo de pesquisa procura estudar. Assim, chegamos a Paulo Freire como uma referência que no nosso entendimento seria importante para o que se pretendia.

O grupo de pesquisa da instituição já realizava estudos a respeito da docência com base em autores como Marcos Masetto, José Carlos Libâneo e Paulo Freire e para a produção deste artigo optamos por analisar e problematizar os dados com base no referencial freiriano. Com isso, buscamos especialmente as seguintes obras: Pedagogia da Autonomia; Pedagogia da Esperança; Pedagogia do Oprimido e Medo e Ousadia, esta última escrita em parceria com Ira Shor. Entendemos que apesar de Paulo Freire ter escrito diversos outros livros, estas obras abarcam de forma satisfatória as construções teóricas do autor em relação à aula.

\section{A Percepção dos Discentes: aula "boa"}

Como referido, conceituar e distinguir o que é uma boa aula de uma ruim nos obriga a adjetivar uma questão que é por si só relativa, pois dependerá sempre da concepção de aula e de educação que o sujeito possui. Por essa razão é que a pesquisa optou por essa terminologia, pois pretendíamos captar por meio das permanências, as noções que mais se repetiam acerca dessa questão. 
Acredita-se com isso que é possível capturar sinais da própria compreensão que os discentes possuam a respeito da educação como um todo. Em outras palavras, o modo como distinguem uma boa aula de uma ruim diz muito da forma como encaram a educação, com que objetivos e sob que influências teóricas, ainda que indiretamente estabelecidas.

Aliás, foi curioso perceber que nenhum aluno, nos 282 questionários respondidos, optou por citar algum teórico na elaboração da sua resposta. As perguntas eram abertas e ofereciam a oportunidade para que algum discente pudesse, ainda que superficialmente, citar alguma referência teórica que o embasasse a responder o que seria uma aula boa ou ruim, mas isso não ocorreu.

Constatamos também que algumas respostas inevitavelmente amparavam-se na percepção que os estudantes possuíam a respeito de seus próprios docentes na Graduação. Isso ficou evidente nos exemplos dados nas respostas. Não raramente, no momento em que definiam as características de uma boa aula, citavam exemplos de iniciativas vivenciadas no percurso da Graduação, ainda que os nomes dos docentes fossem preservados por razões éticas. Sendo assim, aula boa e ruim para os graduandos é uma dimensão que exigiu deles, em determinados momentos, remeter às suas próprias preferências no curso. $\mathrm{Ou}$ seja, querendo ou não os docentes da Graduação, em certa medida, se constituem como modelos/referências aos alunos. O mesmo ocorreu nas elaborações a respeito de aulas ruins.

Ao responderem o que seria uma boa aula e uma ruim, identificamos uma certa similaridade nas respostas em todos os períodos, do primeiro ao sexto. Pareceu haver um padrão de compreensão a respeito dessa questão. E também percebemos uma coerência nas respostas, ou seja, suas compreensões a respeito do que seria uma aula ruim, na prática, eram o inverso do que escreviam no tocante a uma aula boa.

Tanto graduandos de períodos iniciais que ainda não haviam passado por disciplinas como "Didática", ou as disciplinas voltadas a Metodologias de Ensino, como os discentes de períodos avançados, responderam de modo similar essas questões. Os gráficos a seguir ilustram: 
Gráfico 1 - "O que é uma aula boa" - 1 noite

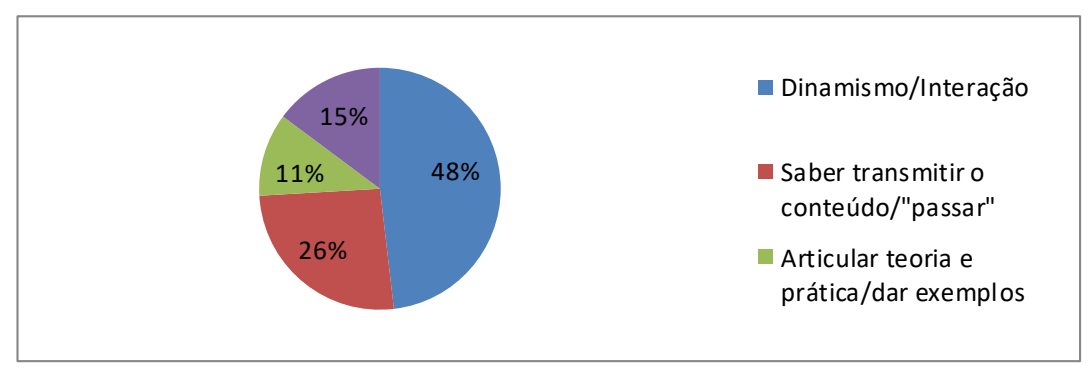

Fonte: Dados da pesquisa, 2017.

Gráfico 2 - "O que é uma aula boa" - $3^{\text {a }}$ noite

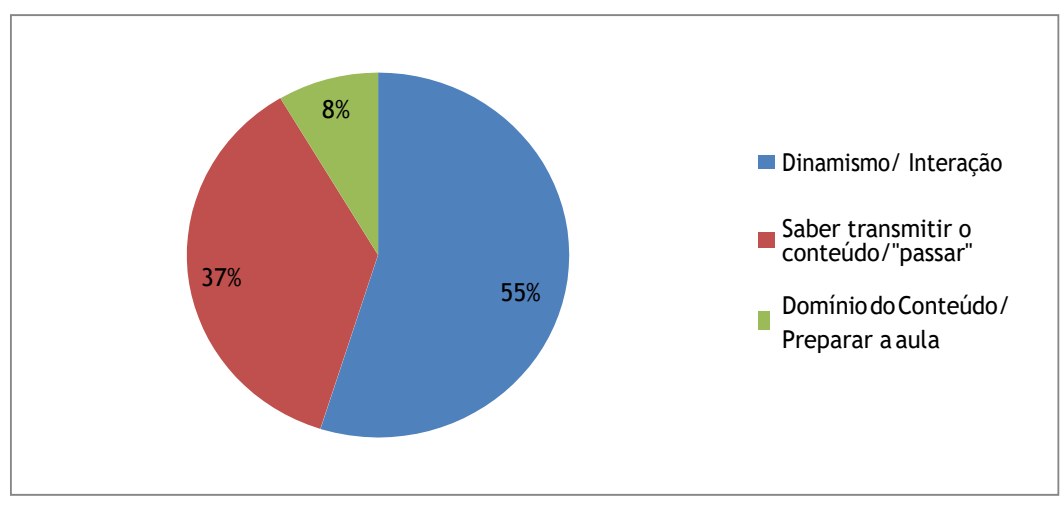

Fonte: Dados da pesquisa, 2017. 
Gráfico 3 - "O que é uma aula boa" - 4" noite

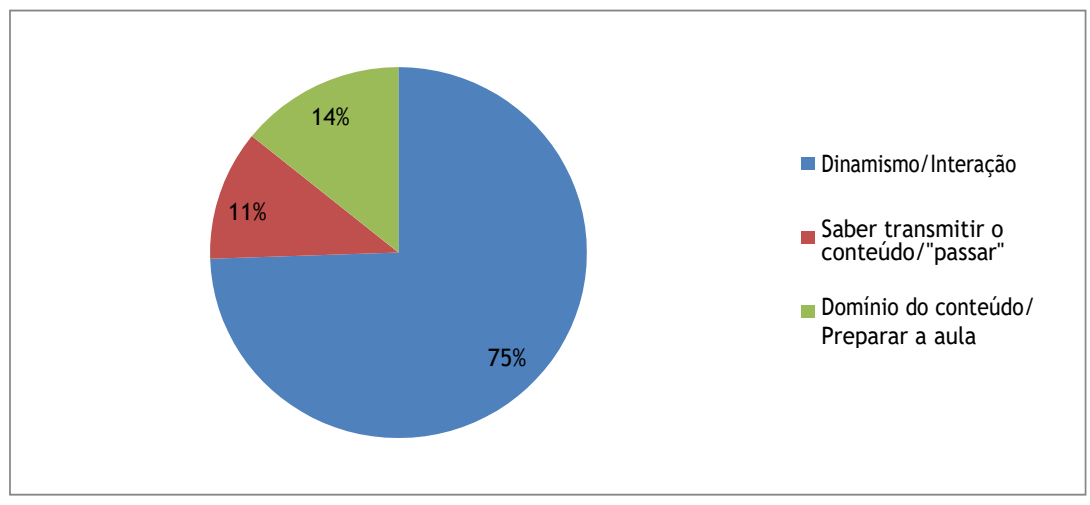

Fonte: Dados da pesquisa, 2017.

Gráfico 4 - "O que é uma boa aula" - 6ª manhã

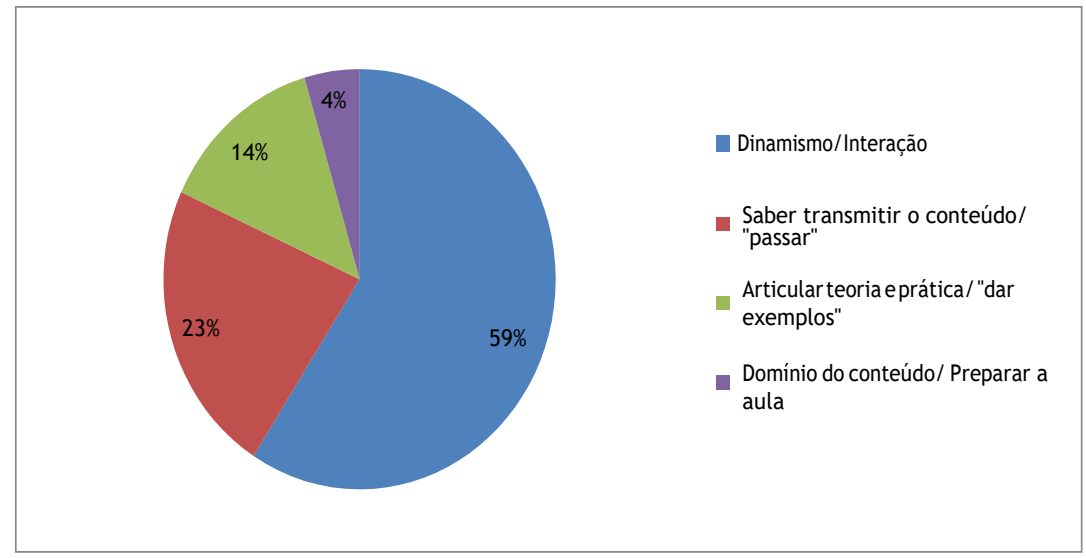

Fonte: Dados da pesquisa, 2017.

Percebe-se claramente nos dados expostos a similaridade nas respostas. Do primeiro ao sexto períodos, a categoria da interação/dinamismo foi sempre o ponto mais lembrado na definição de uma boa aula. Os demais itens se condensam em torno da temática do conteúdo, mas com enfoques distintos: ora abarcando a questão da qualidade na transmissão, ora enfatizando a articulação 
teoria e prática, passando também pela questão do domínio do conteúdo. Ainda assim, a categoria voltada para a transmissão do conteúdo majoritariamente aparece como o segundo ponto mais lembrado pelos estudantes.

Ao responderem a respeito do que seria uma aula ruim, a inversão é claramente percebida. As respostas apontavam para a falta de dinamismo e interação como um ponto central e também para a dificuldade de transmissão do conteúdo como segundo item mais perceptível nas respostas.

Tais termos são complexos e demandariam um aprofundamento ainda maior com os discentes no intuito de compreender com mais detalhes o que percebem por "domínio" de um conteúdo e o que seria essa questão do "saber passar" o conteúdo. É interessante observar que essa expressão "saber passar" foi largamente utilizada e em $20 \%$ dos questionários, de forma isolada. As respostas limitavam-se à seguinte afirmação: "boa aula é aquela em que o professor sabe passar o conteúdo". Na maioria das respostas, porém, tal expressão esteve atrelada à dimensão da interação professor e aluno, sob vias dialógicas.

Transmitir um conteúdo, "saber passá-lo", quando colocado de forma solta como foi em algumas respostas, remete-nos a uma dimensão fortemente subjetiva, em que o discente não consegue explicar em detalhes o que é saber transmitir, mas ele consegue perceber essa transmissão na prática. Entendemos que em muitas respostas os alunos optaram por não escrever em detalhes o que seria essa transmissão, esse "saber passar", por entenderem que tal afirmativa já bastava. Em diálogo com demais respostas, mais detalhadas, infere-se que o "saber passar" está associado a um conjunto de fatores: dinamismo nas aulas, interação com os alunos, capacidade de articular os conteúdos às vivências dos discentes, elaboração de exemplos concretos que dizem da realidade dos estudantes, segurança e domínio no conteúdo transmitido e clareza na exposição.

Responder o que se considera uma aula boa e ruim envolve por parte dos estudantes a opção por fazer escolhas, que por sua vez se associam às suas convicções pedagógicas construídas ao longo do curso. Tais escolhas e seleções são interessantes para se perceber um determinado perfil de docência que emerge. Em meio a essas múltiplas variáveis emergiu então o dinamismo como categoria 
principal em todos os períodos. O dinamismo esteve associado sempre à questão da interação professor-aluno. Este dinamismo/interação partiu sempre de um pressuposto evidenciado nas respostas: a centralidade do professor na aula.

Esta centralidade deve ser entendida de forma dinâmica e interativa, isto é, sem retirar sua responsabilidade no comando da aula, mas sem transformá-la em uma palestra, nos moldes do que Freire (2013) classicamente estabelece como educação bancária. A aula boa para os estudantes de Pedagogia é aquela, essencialmente, em que o docente assume um papel de direção do processo, não delega sua responsabilidade da transmissão dos conhecimentos, mas o faz, didaticamente de forma dinâmica e a todo momento interagindo com os estudantes.

É nesse contexto que a questão do dinamismo/interação aponta como a categoria central nas respostas. Chegar nessa categoria significou condensar percepções muito parecidas, que enfatizavam a capacidade do docente de interagir, de promover uma aula dinâmica com a participação de todos, de dialogar com os alunos, de "usar" os alunos nas aulas, de não "lecionar sozinho", de não "palestrar", de dar aula "conversando com os alunos".

O modo pelo qual os graduandos retrataram a questão do dinamismo/ interação, bem como a centralidade do papel do docente na condução da aula, remeteu-nos a alguns conceitos de Paulo Freire, notadamente os seguintes: diálogo, diretividade e aula (FREIRE, 1992, 1996, 2013; FREIRE; SHOR (1986). Embora nenhum questionário tenha citado teórico algum e mesmo que nem todos expressassem exatamente o termo "dialógico" ao explicarem o que entendem por dinamismo e interação, a noção de diálogo freiriano pôde ser percebida. $\mathrm{O}$ dinamismo diz respeito à capacidade que o docente tem de interagir com a turma e não para a turma. Em outras palavras, essa interação aproxima o sujeito da aula, dialogando com ele, com sua realidade e com suas aspirações, tanto que a capacidade do docente de articular as teorias com situações da realidade foi também um ponto em destaque, o que reforça mais o aspecto freiriano do diálogo contido na noção de dinamismo/interação dos estudantes. Se para Freire (2013) o diálogo se dá na relação de $\mathrm{A} \operatorname{com} \mathrm{B}$, e não A para B, nos questionários foi possível perceber que a interação é justamente a aula do professor com o aluno e não para ele. 
Os discentes demonstraram valorizar a aula expositiva, desde que dialogada. Nesse sentido, valorizam a centralidade do docente no processo. A aula expositiva valorizada é aquela cujo docente dialogicamente exerce seu papel de diretividade nos termos de Freire $(1992,2013)$ e Freire e Shor (1986). Desse modo, o esponteneísmo, isto é, a aula não preparada, cujo docente não sabe bem o que fazer e não a planejou, é tido como um exemplar referencial de aula considerada ruim. Acerca do espontaneísmo, Freire e Shor (1986, p. 53) são categóricos:

\begin{abstract}
Não posso ser espontaneísta! Isto é, não posso deixar os estudantes entregues a si mesmos, por estar tentando ser um educador libertador. Laissez-faire! Não posso cair no laissez-faire. Por um lado, não posso ser autoritário. Por outro lado, não posso cair no laissez-faire. Tenho que ser radicalmente democrático, responsável e diretivo. Não diretivo dos estudantes, mas diretivo do processo no qual os estudantes estão comigo. Enquanto dirigente do processo, o professor libertador não está fazendo alguma coisa aos estudantes, mas com os estudantes.
\end{abstract}

Os discentes mostraram-se muito atentos ao fato de que interação não se trata de algo superficial e raso, não se trata de o professor interagir por meio de "casos" e "piadinhas", ambos citados nos questionários de forma pejorativa. A interação, na análise dos dados, foi percebida no âmbito da transmissão do saber sem um espontaneísmo interativo, que transforma a aula em uma conversa agradável, mas de pouco substrato teórico, ou, nas palavras de um questionário específico: "em uma conversa de comadres, sem conteúdo nenhum".

Em outra obra Freire (1992, p. 58) toca no mesmo ponto:

No segundo caso, temos a anulação da autoridade do professor ou da professora que imerge no já referido clima licencioso e numa prática igualmente licenciosa, em que os educandos, entregues a si mesmos, fazem ou desfazem a seu gosto. Sem limites, a prática espontaneísta, que dilacera algo tão fundamental na formação dos seres humanos - a espontaneidade - não tendo a força suficiente para negar a necessária existência do conteúdo, o leva, porém, a perder-se num jamais justificável "faz-de-conta" pedagógico. 
Ao abordarem essa questão, Freire e Shor (1986) evidenciam o valor que a aula expositiva, desde que dialogada, possui. Nem toda aula expositiva é por si só um exemplar de um tradicionalismo pedagógico. Ao contrário, uma aula expositiva interativa e dinâmica, calcada no diálogo, é algo, nos dizeres freirianos, com potencial libertador:

Ao criticar a educação "bancária", temos que reconhecer que nem todos os tipos de aulas expositivas podem ser considerados educação "bancária". Você pode ser muito crítico fazendo preleções. A questão, para mim, é como fazer com que os alunos não durmam, porque eles nos ouvem como se estivéssemos cantando para eles! A questão não é se as preleções são "bancárias" ou não, ou se não se deve fazer preleções. Porque o caso é que os professores tradicionais tornarão a realidade obscura, quer dando aulas expositivas, quer coordenando discussões. O educador libertador iluminará a realidade mesmo com aulas expositivas. A questão é o conteúdo e o dinamismo da aula, a abordagem do objeto a ser conhecido (FREIRE; SHOR, 1986, p. 71).

O mal, na verdade, não está na aula expositiva, na explicação que o professor ou professora faz. Não é isso que caracteriza o que critiquei como prática bancária. Critiquei e continuo criticando aquele tipo de relação educador-educando em que o educador se considera o exclusivo educador do educando. Em que o educador rompe ou não aceita a condição fundamental do ato de conhecer que é a sua relação dialógica. Por isso mesmo, a relação em que o educador transfere o conhecimento em torno de $a$ ou $b$ ou de $c$ objetos ou conteúdos ao educando, considerado como puro recipiente. Esta é a crítica que fiz e continuo a fazer. O que se pode agora perguntar é o seguinte: será que toda chamada aula expositiva é isso? Acho que não. Digo que não (FREIRE, 1992, p. 61).

O diálogo, para Freire (1992, 1996, 2013), é um princípio pedagógico, muito mais do que uma metodologia do fazer docente. Ele é teórico-metodológico na medida em que é um fundamento epistemológico, mas também oferece saídas concretas aos docentes. Alternativas mais voltadas ao "como fazer", não como uma receita pronta, mas como uma saída ao educador que queira estabelecer o diálogo em sua prática. A dialogicidade pressupõe escuta atenta do outro e a crença naquele outro como um sujeito que tem o direito de dizer 
sua palavra. O diálogo pressupõe, como alerta Freire (1992, 1996, 2013), uma relação educador-educando mediados pelo mundo. Nesse sentido, o educador no viés freiriano não é o mediador do processo de ensino e aprendizagem, algo que reiteradamente é confundido por alguns trabalhos que se apropriam do conceito de diálogo em Paulo Freire, como alerta Scocuglia (2005).

Para Freire e Shor (1986, p. 52), entretanto, o diálogo não existe num vácuo político. "Não é um espaço livre onde se possa fazer o que se quiser. O diálogo se dá dentro de algum tipo de programa e contexto". Esses fatores condicionantes criam uma tensão para alcançar os objetivos que estabelecemos para a educação dialógica. Para alcançar os objetivos da transformação, o diálogo implica responsabilidade, direcionamento, determinação, disciplina e objetivos definidos, e uma situação dialógica implica a ausência do autoritarismo. "O diálogo significa uma tensão permanente entre a autoridade e a liberdade" (FREIRE; SHOR, 1986, p. 52).

Essa tensão alertada por Freire e Shor (1986) significa afirmar que existe sim uma determinada hierarquia entre professor e aluno. Tal condição resulta na diretividade (FREIRE, 1992) do docente no processo da aula. Essa premissa foi amplamente ressaltada nos questionários. A esmagadora maioria das respostas foi em direção do acolhimento da ideia de autoridade do professor sem cair no autoritarismo. As percepções dos discentes encaixam-se satisfatoriamente com o que pensam Freire e Shor (1986, p. 82):

Não sei se os alunos e os professores também lhe perguntam, nessa questão da autoridade na sala de aula dialógica, se o professor é ou não é igual aos estudantes. Essa questão é muito interessante. A experiência de estar por baixo leva os alunos a pensarem que, se você é um professor dialógico, nega definitivamente as diferenças entre eles e você. De uma vez por todas, somos todos iguais! Mas isto não é possível. Temos que ser claros com eles. Não. A relação dialógica não tem o poder de criar uma igualdade impossível como essa. $\mathrm{O}$ educador continua sendo diferente dos alunos, mas - e esta é, para mim, a questão central - a diferença entre eles, se o professor é democrático, se o seu sonho político é de libertação, é que ele não pode permitir que a diferença necessária entre o professor e os alunos se torne "antagônica". A 
diferença continua a existir! Sou diferente dos alunos! Mas se sou democrático não posso permitir que esta diferença seja antagônica. Se eles se tornam antagonistas, é porque me tornei autoritário.

O diálogo é libertador justamente porque pressupõe a interação entre sujeitos sob as mesmas condições e não submetidos a uma hierarquia que exclui um enquanto predomina o outro. É emancipador pois possibilita o dizer da sua palavra. O diálogo não faz desaparecer a diretividade do docente, como assevera Freire $(1992,1996,2013)$. Não se trata de um espontaneísmo conforme percebido, cuja aula sem nenhum direcionamento se constitui em um diálogo livre entre docentes e alunos. A aula expositiva dialogada pressupõe planejamento e direção, e por essa razão, o domínio do conteúdo foi um ponto tão destacado na dimensão da aula boa, e inversamente, a falta de preparo e domínio do docente foi um item bastante lembrado nas respostas relativas às aulas ruins.

Segundo Freire $(1992,1996)$, a necessidade de direção e diretividade-autoridade nos processos educativos nunca significou prepotência, autoritarismo ou arrogância por parte do educador ou de qualquer liderança (inclusive intelectual). Para Scocuglia (2005, p. 91) é "importante colocar, a princípio, a defesa da diretividade do processo educativo, por parte de Freire, como uma das marcas da progressão das suas propostas epistemo-pedagógicas". Nas palavras de Freire (1996, p. 46), é "fato inconteste que a natureza do processo educativo é sempre diretiva", ou seja, o educador tem papel distinto do educando, embora deva estar aberto à sua própria reeducação.

Freire e Shor (1986, p. 87) sintetizam:

Aceitar a natureza diretiva da educação. Existe uma diretividade na educação que nunca lhe permite ser neutra. Temos que dizer aos alunos como pensamos e por que. Meu papel não é ficar em silêncio. Tenho que convencer os alunos do meu sonho, mas não conquistá-los para meus planos pessoais.

Os dados corroboram essa diretividade dialógica como um exemplo do que os discentes consideram uma boa aula. Se percebidos em conjunto com outras categorias, a interação dialógica é valorizada juntamente com outros prismas que dizem, em última instância, do papel central dado à transmissão 
(saber passar), da importância de se "dominar" o conteúdo. Assim, por um lado, a concepção dos discentes é tradicional se entendida no sentido histórico de que o papel do docente como transmissor é algo já retratado na Paideia grega. Por outro lado, foge do tradicionalismo de viés autoritário que marcou algumas pedagogias que centralizavam no docente a aula, por meio de um monopólio da fala e do saber. Em outras palavras, aula boa para estudantes partícipes da pesquisa é aquela em que o docente não perde sua diretividade, mas a exerce de forma interativa-dialógica, com os alunos e não para eles, enxergando-os como sujeitos ativos no processo de ensino-aprendizagem e não como meros depósitos de conhecimento.

A diretividade, nesse ponto, para Freire e Shor (1986), responsabiliza o professor sempre pelo início do processo e ao fazê-lo escancara suas escolhas e seus objetivos, no entanto em nada isso se associa à doutrinação ou manipulação do docente na condução do processo. Freire e Shor (1986, p. 65) explicam:

O professor libertador nem manipula, nem lava as mãos da responsabilidade que tem com os alunos. Assume um papel diretivo necessário para educar. Essa diretividade não é uma posição de comando, de "faça isso" ou "faça aquilo", mas uma postura para dirigir um estudo sério sobre algum objeto, pelo qual os alunos reflitam sobre a intimidade de existência do objeto. Chamo essa posição de radical democrática, porque ela almeja a diretividade e a liberdade ao mesmo tempo, sem nenhum autoritarismo do professor e sem licenciosidade dos alunos. Isto não é dominação. Dominação é se eu dissesse que se deve acreditar nisto porque estou dizendo. Manipulação é dominar os alunos. A manipulação, por exemplo, também cria mitos sobre a realidade. Ela nega a realidade, falsifica a realidade. Manipulação é eu tentar convencer você de que uma mesa é uma cadeira, é o currículo obscurecer a realidade. A aula libertadora, pelo contrário, ilumina a realidade.

Assumir um papel diretivo do processo faz com que a docência não seja produzida sob o viés da neutralidade e desvela a politização do ato educativo (FREIRE, 2013). Nos questionários analisados esse componente político e crítico do papel da aula praticamente inexistiu. Curioso notar que as boas aulas raramente abarcavam a questão da criticidade. Faz-nos deduzir que os futuros profissionais da educação não valorizam de modo substantivo o papel da criti- 
cidade no que vem a ser uma boa aula. Nesse sentido, certamente se distanciam do referencial freiriano. O mesmo Paulo Freire usado por nós para corroborar e endossar percepções dos estudantes de Pedagogia respondentes dos questionários é também recorrido para uma leitura crítica dos dados. O dinamismo/interação como componentes fundamentais de uma boa aula não estiveram a serviço de uma docência crítica, emancipadora. É como se as respostas fossem freirianas até certo ponto, pois não avançaram para a dimensão crucial da teoria freiriana: a criticidade e a compreensão política do ato de educar.

O ato educativo, jamais neutro e, por isso, político em essência, está presente na aula de alguma forma ou de outra. Freire (2013) explica que uma aula pretensamente neutra, na realidade se posiciona implicitamente advogando pela manutenção das estruturas sociais. Quando uma aula opta por estabelecer uma educação bancária com o educando, ou seja, não problematiza, não dialoga com a realidade do estudante e não desvela as ideologias, acaba por se comprometer com a lógica dominante.

A docência crítica nos moldes freirianos, que visa à emancipação e libertação dos sujeitos, via diálogo, compromete-se com toda uma concepção de educação e de sociedade que busca, em última instância, lutar pelo fim da opressão entre classes e por uma outra sociedade calcada em valores de solidariedade, justiça e democracia. A aula é política justamente devido ao fato de ela se inserir na sociedade e, portanto, também poder contribuir para transformá-la. Por essa razão, não basta transmitir conhecimentos por si só, e sim transmiti-los (Paulo Freire nunca negou a importância da socialização dos conhecimentos) de forma problematizadora. Freire e Shor (1986, p. 49), mediante um exemplo esclarecedor, elucidam:

O chamado "padrão" é um conceito profundamente ideológico, mas é necessário ensinar a sua utilização enquanto se criticam, também, suas implicações políticas. Agora, a questão é a seguinte: sabendo de tudo isso, terá o professor libertador o direito de não ensinar as formas padronizadas? Terá o direito de dizer: "Sou um revolucionário, portanto, eu não ensino o ‘bom' inglês?” Não. Do meu ponto de vista, o educador deverá tornar possível o domínio, pelos estudantes, do inglês padrão, mas - e aqui está a grande diferença entre ele e outro professor reacionário - enquanto o professor tradicional ensina as 
regras do inglês de primeira (risadas), ele acentua a dominação dos estudantes pela ideologia elitista, que está inserida nessas regras. O professor libertador lhes ensina a forma padronizada, para que possam sobreviver, discutindo com eles todos os ingredientes ideológicos dessa ingrata tarefa. Você está vendo? Acho que é dessa forma que os professores podem refletir sobre o medo que eles têm da rejeição dos estudantes e também sobre o medo que têm das formas padronizadas.

A dimensão da criticidade foi esquecida nos questionários. Não foi lembrada nem no momento de responder a respeito do que seria uma aula boa, valorizando tal dimensão, nem no tocante à aula ruim. Nas 282 respostas analisadas, nenhuma mencionou sequer a palavra "crítica", o que consideramos ser, no mínimo, curioso e surpreendente, em se tratando de um curso de formação de professores. Até mesmo porque as respostas não caminharam para uma noção de docência conservadora e autoritária, o que justificaria, a priori, a ausência da valorização da criticidade. Entendemos, portanto, que há uma espécie de despolitização da noção de docência por parte dos estudantes de Pedagogia participantes da pesquisa. Há uma interessante articulação entre diálogo, interação, dinamismo e diretividade, mas sem avançar para a dimensão da crítica.

Imaginamos que ao captar a percepção de discentes de um curso de Pedagogia sobre o que venha a ser boa aula, isto diz algo do perfil de docente que pretendem ser. Não há sentido em valorizar como uma boa aula os aspectos da interação dialógica, do domínio do conteúdo e na própria prática profissional se constituir um docente que apresente atributos opostos. Dessa forma, na valorização extrema do dinamismo e no esvaziamento total da criticidade, eis um convite de Paulo Freire para uma compreensão de docência mais crítica:

Esta é a dialética da sala de aula libertadora. É um lugar em que pensamos criticamente sobre as forças que interferem em nosso pensamento crítico. Assim, as salas de aula libertadoras iluminam as condições em que nos encontramos para ajudar-nos a superar essas condições. Este é o convite que fazemos aos estudantes (FREIRE; SHOR, 1986, p. 81). 
Tal convite é feito por Paulo Freire ao responder a uma indagação de Ira Shor na obra em parceria dos dois autores. Tal passagem é esclarecedora do potencial de uma aula para além da questão do dinamismo e da interação, embora características também muito importantes.

\section{Considerações Finais}

Foi objetivo deste artigo analisar as respostas que discentes de Pedagogia deram para as questões: O que é uma boa aula para você?; O que é uma ruim para você? Conseguimos perceber nos dados uma coerência: a valorização de aspectos centrais a uma boa aula corresponde justamente ao inverso daquilo compreendido como aula ruim. Em outras palavras, se aula boa é considerada pelos estudantes como aquela que interage e é dinâmica, aula ruim, por sua vez, é uma aula cansativa, parada, em que não há nenhum dinamismo.

Reiteramos aqui que não queremos com isso reduzir a Pedagogia à docência, e sim, ressaltar esta importante temática na visão de seus estudantes. Toda pesquisa carrega em si suas imprecisões e desafios. Procuramos nos cercar de um bom embasamento teórico-metodológico para diminuir ao máximo as lacunas que podem ocorrer em pesquisas típicas das Ciências Humanas. Desse modo, tratamos qualitativamente 282 respostas abertas contidas no questionário, especificamente no eixo pedagógico. Produzir tais dados, conforme já explicado, não seria possível sem o recurso da análise de conteúdo para criação de categorias (BARDIN, 2011).

É curioso perguntar ao discente de um curso de Pedagogia o que ele compreende por aula boa e ruim. Curioso por que, como aluno, tal estudante passou toda sua educação básica e superior assistindo aulas, de múltiplas formas, mas o próprio estudante será um pedagogo e muito provavelmente atuará na docência. Sendo assim, as aulas que assiste ganham outro componente: a observação sistemática das condutas de seus docentes na Graduação de modo a lhes servirem de algum tipo de estímulo. 
Os discentes, ao produzirem suas respostas, moldam também o perfil de docente que almejam ser, embora esta equação não garanta uma concretude na prática. Ilustra, no entanto, e dá pistas de uma concepção de professor idealizada.

Categorizar as respostas abertas, por um lado, possibilita uma análise mais didática dos dados; por outro, tende a fragmentar algo que precisa ser compreendido como um todo. Assim, salientamos que no aspecto total das respostas houve uma espécie de característica docente percebida: uma boa aula seria aquela em que o professor consegue interagir dialogicamente com a turma, sem perder sua diretividade, isto é, seu papel de liderança do processo, ainda que tal papel não signifique uma liderança autoritária e centralizadora. $\mathrm{O}$ docente, dessa forma, deve dominar seu conteúdo e transmiti-lo, não podendo abdicar desse papel, mas não pode deixar de fazê-lo sem a participação de seus alunos, estabelecendo um diálogo com eles e não para eles.

Sabemos que as contradições entre o que se diz e o que se faz são até certo ponto comuns no campo educacional, mas ainda assim reiteramos aqui a crença de que tais respostas indiquem, ao menos, uma tendência de futuros profissionais da educação a se tornarem docentes que conciliem a interação dialógica com seus futuros alunos, sem se descuidar da diretividade do docente e de sua responsabilidade no preparo de uma aula, que possua substrato teórico sem deixar de articular com as vivências daqueles que interagem.

\section{Referências}

BARDIN, Laurence. Análise do conteúdo. Tradução Luis Antero Reto. São Paulo: Edições 70, 2011.

BRASIL. Resolução CNE/CP 1/2006. Institui as Diretrizes Curriculares Nacionais para o curso de Graduação em Pedagogia, licenciatura. Diário Oficial da União, Brasília, 16 maio 2006, Seção 1, p. 11.

CHIZZOTTI, Antônio. Pesquisa qualitativa em ciências humanas e sociais. Petrópolis, RJ: Vozes, 2008.

FLORES, Cezar Augusto da Silva. O perfil socioeconômico dos estudantes ingressantes do curso de pedagogia da Universidade do Estado de Mato Grosso - Campus universitário de Sinop, no ano de 2014. Revista Eventos Pedagógicos, v. 6, n. 2 (15. ed.), p. 52-61, 2015. 
FRANCO, Maria Amélia; LIBÂNEO, José Carlos; PIMENTA, Selma Garrido. Elementos para a formulação de diretrizes curriculares para cursos de pedagogia. Cadernos de Pesquisa, v. 37, n. 130, p. 63-97, jan./abr. 2007.

FREIRE, Paulo; SHOR, Ira. Medo e ousadia - o cotidiano do professor. Rio de Janeiro: Paz e Terra, 1986.

FREIRE, Paulo. Pedagogia da esperança. 11. ed. São Paulo: Paz e Terra, 1992.

Pedagogia da autonomia: saberes necessários à prática educativa. São Paulo: Paz e Terra, 1996.

. Pedagogia do oprimido. 33. ed. Rio de Janeiro: Paz e Terra, 2013.

GIL, Antônio Carlos. Como elaborar projetos de pesquisa. São Paulo: Atlas, 2002.

GOMES, Romeu. A análise de dados em pesquisa qualitativa. In: MINAYO, Maria Cecília de Souza (Org.). Pesquisa social: teoria, métodos e criatividade. 15. ed. Petrópolis, RJ: Vozes, 2000.

GUTIERRES, Juliana Diniz et al. O perfil dos alunos do curso de Pedagogia da Furg. In: SEMINÁRIO DE PESQUISA EM EDUCAÇÃO DA REGIÃO SUL, ANPED SUL 9. Porto Alegre, Anped, 2012.

LAKATOS, Eva Maria; MARCONI, Marina Andrade. Técnicas de pesquisa. 7. ed. São Paulo: Atlas, 2005.

LIBÂNEO, José Carlos. Diretrizes Curriculares da Pedagogia: imprecisões teóricas e concepção estreita da formação profissional de educadores. Educ. Soc., Campinas, vol. 27, n. 96, p. 843-876, 2006.

MASETTO, Marcos Tarciso. Competência Pedagógica do Professor Universitário. 4. reimpressão. São Paulo: Editora Sammus Editorial, 2003.

REIS, Márcia Santos Anjo; MEDEIROS, Cynthia Moraes. Perfil dos alunos ingressantes do curso de Pedagogia do campus Jataí/UFG no período de 2004 a 2008. Revista Eletrônica do Curso de Pedagogia do Campus Jataí da Universidade Federal de Goiás, v. 2, n. 11, 2011.

SANTOS, Gisele Caroline Nascimento; VELANGA, Carmen Tereza. Perfil dos discentes e docentes do curso de Pedagogia da Universidade Federal de Rondônia. ENCONTRO DE PÓS-GRADUAÇÃO EM EDUCAÇÃO, 1., Semana Educa "Políticas Educacionais e Formação Docente na/para Diversidade”. Porto Velho, Rondônia, 2010.

SAUL, Ana Maria. Paulo Freire na atualidade: legado e reinvenção. Revista e-Curriculum, São Paulo, v. 14, n. 1, p. 9-34, 2016.

SCOCUGLIA, Afonso Celso. Paulo Freire e a conscientização na transição pós-moderna. Educação, Sociedade \& Culturas, n. 23, p. 21-42, 2005.

TANURI, Leonor. História da formação de professores. Revista Brasileira de Educação. Rio de Janeiro, n. 14, p. 61-88, maio/ago. 2000. 